\title{
Modern discrimination: how perpetrators and targets interactively perpetuate social disadvantage Naomi Ellemers ${ }^{1}$ and Manuela Barreto ${ }^{2}$
}

\begin{abstract}
Stereotypes and discriminatory behavior do not necessarily imply that people are explicitly devalued or actively excluded from attractive positions in society. Instead, these often implicitly communicate that any social disadvantages are due to individual shortcomings. Recent research has uncovered a number of mechanisms that explain how individuals may come to enact stereotypical expectations of others. Modern expressions of stereotypes are not easily recognized or perceived as discriminatory. Attempts to distance the self from the disadvantaged group to avoid discrimination are likely to backfire in different ways. Countering common beliefs, people are quite reluctant to confront discrimination or to claim unequal treatment. For all these reasons, modern discrimination tends to induce a cycle of self-fulfilling mechanisms that perpetuate group-based social disadvantage.
\end{abstract}

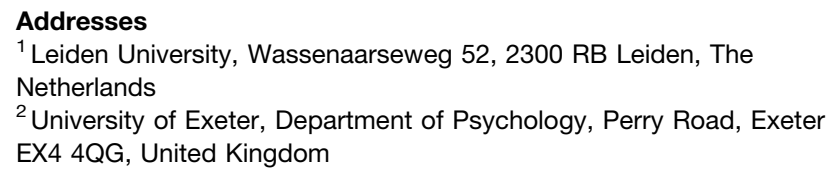

${ }^{2}$ University of Exeter, Department of Psychology, Perry Road, Exeter EX4 4QG, United Kingdom

Corresponding author: Ellemers, Naomi (Ellemers@fsw.leidenuniv.nl, M.Barreto@exeter.ac.uk)

\section{Current Opinion in Behavioral Sciences 2015, 3:142-146 \\ This review comes from a themed issue on Social behavior \\ Edited by Molly J Crockett and Amy Cuddy \\ For a complete overview see the Issue and the Editorial \\ Available online 13th April 2015 \\ http://dx.doi.org/10.1016/j.cobeha.2015.04.001 \\ 2352-1546/C 2015 Elsevier Ltd. All rights reserved.}

\section{Introduction}

Many societies these days have legal provisions prohibiting discrimination. Different types of organizations have formal guidelines aiming to prevent unequal treatment. Hence, we tend to think stereotyping and discrimination are a thing of the past [1]. At the same time, we can all see that migrants or women are underrepresented in certain professions or job levels [2,3]. Statistics show their hourly wages are consistently lower than those of white males at every job level [4]. The conviction that everyone has equal opportunities to succeed, together with the observation that some are less successful than others can only convey one thing: That any differences in important societal outcomes, such as jobs, income, housing, or health status must be ascribed to individual differences in people's abilities, ambitions, or priorities [5].

As a result, the focus of attempts to avoid unequal outcomes has shifted. Instead of addressing stereotypes held by members of advantaged groups, nowadays social equality is pursued by trying to increase the competencies of those who are disadvantaged. At the same time, scientific research has been unable to establish evidence for reliable differences between different groups in relevant abilities or ambitions [6 $6^{\bullet \bullet}$. Hence, 'fixing' individual shortcomings does not seem to offer a satisfactory solution for the systematic inequality of outcomes achieved by members of different social groups.

Recent research helps understand what should be more effective. It has established that - instead of being a thing from the past - the nature of stereotypes and the way these lead to discrimination has shifted [7]. Instead of 'perpetrators' explicitly devaluing and excluding 'targets' $\left[8^{\bullet}, 9^{\bullet}\right]$, there is a much more subtle and implicit cycle of group-based social expectations that tends to undermine the self-confidence of those who are disadvantaged and impedes their ability to perform well $[10,11]$ (see Figure 1). In fact, these more subtle and implicit group-based expectations often seem innocent and accurate, and tend to be endorsed by those who are advantaged as well as those who suffer from them [12].

\section{Modern stereotyping}

We tend to think of stereotyping and discrimination as blatantly negative views of others ('immigrants are lazy', 'women lack ambition') that make people reluctant to accept them into their neighborhood, or to respect them as colleagues at work. Nowadays, many of us no longer endorse such views. Instead, we are motivated to be unprejudiced, and hope to provide equal treatment for all [13]. Yet we unwittingly ascribe characteristics to individuals that seem to fit their group membership. In turn, these biased associations are more predictive of our actual behavior toward others than the stated intention to provide equal treatment [14].

Thus, stereotypical views have shifted toward more implicit forms of bias [15]. Instead of emphasizing the shortcomings of devalued groups in society, modern stereotypes emphasize and celebrate domains of excellence considered typical for these groups (e.g. sports or 
Figure 1

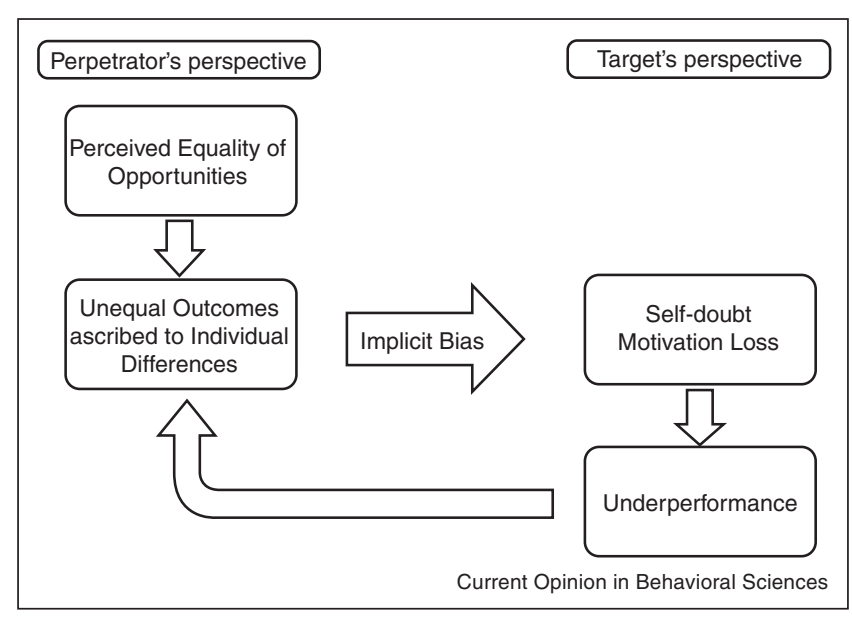

How denial of discrimination perpetuates unequal outcomes.

music for migrants, care activities for women) [16]. At the same time, such features are clearly less useful to obtain important educational or societal outcomes [17].

Exposure to implicit bias elicits anxiety, and increases concerns about one's abilities. This depletes people's cognitive resources and results in performance loss $[18,19]$. The fact that so few individuals originating from disadvantaged groups are successful, impacts on our expectations regarding the potential of other group members [20]. Over time, such common expectations of characteristic group features easily turn into prescriptive norms. Individuals who violate stereotypical expectations (professional women; stay-at-home dads) tend to be evaluated negatively, or are seen as disloyal to their group ('oreo's' - blacks 'acting white'). Even if modern stereotypes are subtle and implicit, they are not harmless. Research has convincingly documented the negative impact subtle discrimination has on individual well-being (self-esteem, life satisfaction [21 $\left.{ }^{\bullet \bullet}\right]$ ) and on indicators of psychological and physical health relevant to performance in educational and work settings [22].

\section{Perceiving discrimination}

Stereotypes and prejudice can be expressed in different ways. Some are very implicit and subtle, and may seem innocuous [23]. They can take the form of compliments (emphasizing the appearance rather than the competence of women in a work context), or jokes (making fun of cultural practices). Such forms of prejudice do not necessarily communicate negative views of these groups. In fact, individuals who belong to disadvantaged groups may also endorse stereotypes that pertain to their own group, and hence think unequal outcomes are fair $\left[24^{\circ}\right]$. We tend not to recognize these beliefs as being biased [25].
It is difficult to overcome stereotypical associations [26], yet most people will not easily admit (even to themselves!) that their preferences and decisions are co-determined by people's group memberships. Furthermore, 'perpetrators' as well as 'targets' typically only have case-by-case experiences, while aggregate information is required to detect group-level disadvantage [27]. Consequently, modern discrimination tends to remain unnoticed [28].

Nevertheless, experimental studies reveal that candidates with identical qualifications are rated differently, depending on their presumed group membership (John vs. Jennifer, [29]). Likewise, experiments with mock job applications make it possible to expose people to biased decision making, in order to examine whether they perceive discrimination when it occurs. This has revealed that people tend to under-estimate rather than overestimating the occurrence of group-level discrimination $\left[30^{\circ}\right]$. Additionally, the presence of representatives of undervalued groups $\left[31^{\circ}\right]$, or of measures aiming to secure equal treatment, for instance in organizations, paradoxically makes us less vigilant against bias, and less likely to note discrimination when it occurs [32].

\section{Avoiding discrimination}

People often have multiple identities. They can simultaneously be a migrant and national citizen, a mother and a manager, or a homosexual and a school teacher [33]. Although these identities are not necessarily incompatible, they are often regarded as such [34]. Individuals are generally expected to adapt to demands, for instance associated with their work role, by ignoring other roles that are important for their identity [35].

As a result, individuals may come to denounce immediately visible group memberships (based on gender or race), or to conceal less visible group memberships (social background, sexual preferences) to avoid group-based discrimination [36]. This happens when female workers emphasize their competence or ambitions as being superior to those of other women [37], or when homosexuals take pains not to reveal their sexual orientation at work. Individuals adopt this strategy as they think it may help them escape discrimination. Nevertheless, there are important psychological and interpersonal costs associated with such strategies, which actually increase the likelihood of social rejection [38]. Distancing the self from others who suffer similar fates makes people forfeit important sources of social support [39]. Rumination, stress, or guilt about hiding one's 'true self' is distracting. This undermines the ability to perform well [40], and damages mental and physical health [41]. When successful individuals present themselves as being exceptional, this also reinforces stereotypical expectations about other members of their group [42] (see Figure 2). 
Figure 2

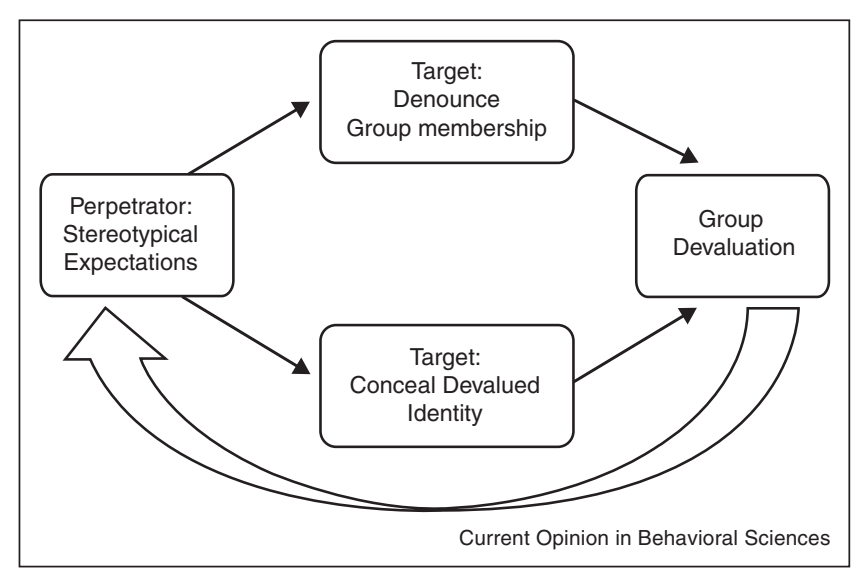

How attempts to avoid discrimination confirm stereotypical expectations.

\section{Confronting discrimination}

We tend to assume that discrimination is obvious, that people will protest against bias, and that an absence of complaints implies equal treatment [43]. For all the reasons cited above, these are not valid assumptions [44]. Discriminatory practices rarely are as clear or explicit as is often presupposed, for instance in anti-discrimination legislation. Two job candidates never have identical qualifications, with the only difference between them their gender or ethnicity. Targets of discrimination often do not recognize bias, and are more likely to under-report than over-report unequal treatment [45]. Yet they are expected to take the initiative to expose or rectify discriminatory practices they encounter.

For those who are excluded from important opportunities in life, it is not so easy to complain. Paradoxically, people have to feel secure in their belongingness needs, before they seek respectful treatment or feel free to confront discriminatory treatment [46]. Thus, while system level changes rely on individuals who confront discrimination, those who complain about unequal treatment incur important social costs [47]. Targets who confront discrimination are disliked by observers, even if their complaints are valid $[48,49]$.

\section{Conclusion}

Prior efforts have aimed to understand how the endorsement of stereotypes can be reduced (from the perspective of the perpetrator), or how discrimination may be avoided (from the perspective of the target). During the past years, it has become clear that instead we need to address the interaction between these two perspectives. Recent research has revealed the self-defeating cycles through which implicitly biased views (held by perpetrators) may elicit stereotype confirming behavior (among targets). As a result, the lower societal outcomes of members of devalued groups in society are not easily traced back to overt discrimination. Instead, these seem to reflect individual differences in competence or ambition. Findings from different studies demonstrate that the insistence that all individuals have equal opportunities to achieve, in itself constitutes a form of discrimination that perpetuates group-based inequality. Specifically, it has been established that stereotyping and discrimination may be expressed implicitly and are not easily recognized.

Individuals who try to avoid discrimination by denouncing or concealing their stigmatized identity deprive themselves of social support, and suffer in terms of well-being and performance. When they are successful, this does not benefit the image we have of other members of their group. Relying on targets of discrimination to expose or confront unequal treatment presupposes their awareness of implicit bias. It also places the burden of system change - including the social cost of being the bearer of bad news - on the targets instead of the perpetrators of unequal treatment. In sum, recent research reveals that it is not realistic to rely on our desire to provide equal treatment to all. Nor is it reasonable to place the responsibility for identifying and confronting discrimination on those who suffer from it. Instead, we should take advantage of scientific evidence on the implicit nature and farreaching implications of modern discrimination, to provide more effective strategies to combat group-based inequality [50].

\section{Conflict of interest}

The authors declare that there is no conflict of interest in preparing this submission.

\section{Acknowledgments}

The contribution of Naomi Ellemers to this manuscript was supported by a KNAW/SNS-REAAL Merian Award and a Spinoza Award; the research of Manuela Barreto was supported by an NWO Vernieuwingsimpuls grant (VI 016.025.021).

\section{References and recommended reading}

Papers of particular interest, published within the period of review, have been highlighted as:

- of special interest

$\bullet$ of outstanding interest

1. Stroebe KE, Dovidio JF, Barreto M, Ellemers N, John M-S: Is the world a just place? Countering the negative consequences of pervasive discrimination by affirming the world as just. $\mathrm{Br} J$ Social Psychol 2010, 50:484-500.

2. Catalyst: Pyramid: US Women in Business. New York: Catalyst; 2014:. http://www.catalyst.org/knowledge/ us-women-business-0.

3. Hoyt CL: Women, men, and leadership: exploring the gender gap at the top. Social Personal Psychol Compass 2010, 4:484-498

4. Kulich C, Trojanowski G, Ryan MK, Haslam SA, Renneboog LDR: Who gets the carrot and who gets the stick? Evidence of gender disparities in executive remuneration. Strategic Manage J 2011, 32:301-321. 
5. Crosby FJ, Sabattini L, Aizawa M: Affirmative action and gender equality. In The SAGE Handbook of Gender and Psychology. Edited by Ryan MK, Branscombe NR. London: Sage Publications; 2013:484-499.

6. Hyde JS: Gender similarities and differences. Annu Rev Psychol •. 2014, 65:373-398.

This paper provides a review of meta-analyses, providing consistent evidence for gender similarities (instead of gender differences) in careerrelevant attributes, such as math ability, academic self-confidence, and leadership abilities.

7. Barreto M: Experiencing and coping with social stigma. In APA Handbook of Personality and Social Psychology, Volume 2: Group Processes. Edited by Mikulincer M, Shaver PR, Dovidio JF, Simpson JA. American Psychological Association; 2014:473-506 http://dx.doi.org/10.1037/14342-018.

8. DiTomaso N: The American Non-dilemma: Racial Inequality - Without Racism. Russell Sage Foundation; 2013.

This book shows how African Americans in the US are unable to rely on social networks and support systems that are available for Caucasian Americans, and how this impacts upon their individual opportunities to succeed in the American society.

9. Greenwald AG, Pettigrew TF: With malice toward none and - charity for some. Am Psychol 2014, 69:669-684.

This paper argues how ingroup favoritism, rather than outgroup hostility, is the main explanatory factor in modern-day discrimination.

10. Koch SC, Konigorski S, Sieverding M: Sexist behavior undermines women's performance in a job application situation. Sex Roles 2014, 70:79-87.

11. Van Laar C, Derks B, Ellemers N: Motivation for education and work in young Muslim women: the importance of value for ingroup domains. Basic Appl Psychol 2013, 35:64-74.

12. Ellemers N, Van Laar C: Individual mobility: the opportunities and challenges members of devalued groups encounter when trying to avoid group-based discrimination. In Handbook of Prejudice, Stereotyping, and Discrimination. Edited by Dovidio JF, Hewstone M, Glick P, Esses V. London: Sage; 2010: 561-576.

13. Van Nunspeet F, Ellemers N, Derks B, Nieuwenhuis S: Moral concerns increase attention and response monitoring during IAT performance: ERP evidence. Social Cogn Affect Neurosci 2014, 9:141-149.

14. Greenwald AG, Poehlman TA, Uhlmann EL, Banaji MR: Understanding and using the Implicit Association Test: III. Meta-analysis of predictive validity. J Personal Social Psychol 2009, 97:17-41.

15. Leslie SJ, Cimpian A, Meyer M, Freeland E: Expectations of brilliance underlie gender distributions across academic disciplines. Science 2015, 347:262-265.

16. Folbre N: Should women care less? Intrinsic motivation and gender inequality. Br J Ind Relat 2012, 50:597-619.

17. Ellemers N: Women at work: how organizational features impact career development. Policy Insights Behav Brain Sci 2014, 1:46-54

18. Schmader $\mathrm{T}$, Hall $\mathrm{H}$, Croft $\mathrm{A}$ : Stereotype threat in intergroup relations. In APA Handbook of Personality and Social Psychology, Volume 2: Group Processes. Edited by Mikulincer M, Shaver PR, Dovidio JF, Simpson JA. American Psychological Association; 2014:447-471.

19. Ståhl T, Van Laar C, Ellemers N: How stereotype threat affects cognitive performance under a prevention focus: initial cognitive mobilization is followed by depletion. J Personal Social Psychol 2012, 102:1239-1251.

20. Miller DI, Eagly AH, Linn MC: Women's representation in science predicts national gender-science stereotypes: evidence from 66 nations. J Educ Psychol 2014. http:// dx.doi.org/10.1037/edu0000005.

21. Schmitt MT, Branscombe NR, Postmes T, Garcia A: The

-. consequences of perceived discrimination for psychological wellbeing: a meta-analytic review. Psychol Bull 2014, 140:921-948.
This meta-analysis reviews evidence from experimental as well as correlational field studies documenting how discrimination experiences impact upon individual well-being.

22. Jones KP, Peddie Cl, Gilrane VL, King EB, Gray AL: Not so subtle: a meta-analytic investigation of the correlates of subtle and overt discrimination. J Manage $2013 \mathrm{http} / / / \mathrm{dx}$.doi.org/10.1177/ 0149206313506466.

23. Barreto M, Ellemers N: Sexism in contemporary societies: how it is expressed, perceived, confirmed, and resisted. In The SAGE Handbook of Gender and Psychology (Chapter 18). Edited by Ryan M, Branscombe N. SAGE Pubs; 2013:288-305 http:// dx.doi.org/10.4135/9781446269930.

24. Heilman ME: Gender stereotypes and workplace bias. Res Organizational Behav 2012, 32:113-135.

This paper explains how differential expectations about the abilities of men and women may induce unequal career opportunities at work.

25. Stephens NM, Levine CS: Opting out or denying discrimination? How the framework of free choice in American society influences perceptions of gender inequality. Psychol Sci 2011, 22:1231-1236.

26. Gonsalkorale K, Sherman JW, Allen TJ, Klauer KC, Amodio DM: Accounting for successful control of implicit racial bias: the roles of association activation, response monitoring, and overcoming bias. Personal Social Psychol Bull 2011, 37:15341545.

27. Ceci SJ, Ginther DK, Kahn S, Williams WM: Women in academic science: a changing landscape. Psychol Sci Public Interest 2014, 15:75-141.

28. Jetten J, lyer A, Branscombe NR, Zhang A: How the disadvantaged appraise group-based exclusion: the path from legitimacy to illegitimacy. Eur Rev Social Psychol 2013, 24:194-224.

29. Moss-Racusin CA, Dovidio JF, Brescoll VL, Graham MJ, Handelsman J: Science faculty's subtle gender biases favor male students. Proc Natl Acad Sci 2012, 109:16474-16479.

30. Barreto M, Ellemers N: In Detecting and Experiencing Prejudice:

- New Answers to Old Questions, 52. Edited by Olson J, Zanna M. 2015.

Advances in Experimental Social Psychology. This paper provides an extensive review of the empirical work supporting the arguments presented in this Current Opinion contribution.

31. Kaiser CR, Major B, Jurcevic I, Dover TL, Brady LM, Shapiro JR:

- Presumed fair: ironic effects of organizational diversity structures. J Personal Social Psychol 2013, 104:504-519.

This paper shows how the presence of diversity measures makes people less vigilant against bias and hence elicits discrimination.

32. Castilla EJ, Benard S: The paradox of meritocracy in organizations. Admin Sci Quart 2010, 55:543-576.

33. Lyness KS, Judiesch MK: Gender egalitarianism and work-life balance for managers: a multisource perspective in 36 countries. Appl Psychol Int Rev 2014, 63:96-129.

34. Kahn JR, García-Manglano J, Bianchi SM: The motherhood penalty at midlife: long-term effects of children on women's careers. J Marriage Family 2014, 76:56-72.

35. Shih M, Young MJ, Bucher A: Working to reduce the effects of discrimination: identity management strategies in organizations. Am Psychol 2013, 68:145-157.

36. Ellemers N, Rink F, Derks B, Ryan M: Women in high places: when and why promoting women into top positions can harm them individually or as a group (and how to prevent this). Res Organizational Behav 2012, 32:163-187.

37. Derks B, Van Laar C, Ellemers N, De Groot K: Gender bias primes elicit Queen Bee responses among senior police women. Psychol Sci 2011, 22:1243-1249.

38. Newheiser A-K, Barreto M: Hidden costs of hiding stigma: ironic interpersonal consequences of concealing a stigmatized identity in social interactions. J Exp Social Psychol 2014, 52:58-70. 
39. Van Laar C, Bleeker D, Ellemers N, Meijer E: Ingroup and outgroup support for upward mobility: divergent responses to ingroup identification in low status groups. Eur J Social Psychol 2014, 44:563-577.

40. Jones KP, King EB: Managing concealable stigmas at work: a review and multilevel model. J Manage 2014, 40:1466-1494.

41. Sedlovskaya A, Purdie-Vaughns V, Eibach RP, LaFrance M, Romero-Canyas R, Camp NP: Internalizing the closet: concealment heightens the cognitive distinction between public and private selves. J Personal Social Psychol 2013, 104:695-715.

42. Derks B, Ellemers N, Van Laar C, De Groot K: Do sexist organizational cultures create the Queen Bee? Br J Social Psychol 2011, 50:519-535.

43. Cihangir S, Barreto M, Ellemers $\mathrm{N}$ : Men as allies against sexism the positive effects of a suggestion of sexism by male (vs. female) sources. Sage Open 2014, April-June:1-12.

44. Kahn KB, Barreto M, Kaiser CK, Rego MS: When do high and low status group members support confrontation? The role of perceived pervasiveness of prejudice. $\mathrm{Br} J$ Social Psychol, in press.
45. Swim JK, Eyssell KM, Quinlivan E, Ferguson MJ: Self-silencing to sexism. J Social Issues 2010, 63:493-507.

46. Mallett RK, Melchiori KJ: Goal preference shapes confrontations of sexism. Personal Social Psychol Bull 2014, 40:646-656.

47. Rasinski HM, Geers AL, Czopp AM: “I guess what he said wasn't that bad": dissonance in nonconfronting targets of prejudice. Personal Social Psychol Bull 2013, 39:856-869.

48. Rasinski HM, Czopp AM: The effect of target status on witnesses' reactions to confrontations of bias. Basic Appl Social Psychol 2010, 32:8-16.

49. Garcia DM, Schmitt MT, Branscombe NR, Ellemers N: Women's reactions to ingroup members who protest discriminatory treatment: the importance of beliefs about inequality and response appropriateness. Eur J Social Psychol 2010, 40:733-745.

50. Moss-Racusin CA, Van der Toorn J, Dovidio JF, Brescoll VL, Graham MJ, Handelsman J: Scientific diversity interventions. Science 2014, 343:615-616. 